\title{
Comparative Study of Agility among Korfball and Netball Players in Hyderabad India
}

\author{
Loka Bavoji Laxmikanth Rathod \\ Principal Nizam College \\ Osmania University \\ Hyderabad, India. \\ rathodlb@rediffmail.com
}

\begin{abstract}
- the purpose of this study is to determine the effect of agility among Korfball players and netball players of Hyderabad District in India. Twenty (20) male korfball players and twenty (20) male netball players were used as samples for this study. The Illinois Agility Test was used to conduct agility test for both groups. The result of this study shows that netball players have good agility compare to korfball players. Playing netball is just like playing basketball, but there is no dribbling once a player has the ball, because they are not allowed to take more than a single step. Speed and agility are of a great importance because it helps players to stay open to get the ball, and make a great shot. Players are also not allowed to hold the ball longer than three seconds; therefore, speed and optimal reaction time are critical.
\end{abstract}

Keywords—speed, dribbling, agility, korfball, netball

\section{INTRODUCTION}

Korfball is a ball sport with similarities to netball and basketball; and it is played by two teams of eight players each with either eight females in each team, or with four females and four males in each team. The objective of this sport is to throw a ball through a bottomless basket that is mounted on a $3.5 \mathrm{~m}$ (11.5 feet) high pole. This sport was invented by a Dutch school teacher, Nico Broekhuysen in 1902. In the Netherlands, there are around 580 clubs and 100,000 people that play korfball. Korfball has a mixedgender league and all-women league, but no all-men league. The sport is very popular in Belgium and Taiwan and it is also played in many other countries. Mixed-gender korfball is generally played in the north of Netherlands, while all-female korfball is generally played in the south Netherlands.

Netball is a ball sport played by two teams of seven players each. The development of netball began in England in 1890 s, and it is derived from early versions of basketball. In 1960, international playing rules were standardized for the game and the International Federation of Netball and Women's Basketball was formed. As of 2011, the INF comprises of more than 60 teams organized into five global five global regions.

Netball games are played on a rectangular court with raised goal rings at each end. To make an attempt to score goals, a ball is passed down the court and it will be shot through its goal ring. Players are assigned specific positions to define their roles within the team, and to restrict their movement to certain areas of the court. During a general play, the player with the ball can hold onto it for only three seconds before shooting for a goal or passing it to another player. The winning team is the team that scores the most goals. Netball games are only 60 minutes long and variations have been developed to increase the game's pace so that it can appeal to a wider audience.

Netball is the most popular game in Commonwealth nations, specifically in schools; and it is predominantly played among women. According to the INF, netball is played by more than 20 million people in more than 80 countries. Major transnational competition takes place including the Netball Super league in Great Britain, and the ANZ Championship in Australia and New Zealand. There are three

major international competitions that take place, these are: the quadrennial World Netball Championships, the Commonwealth Games, and the yearly World Netball Series. In 1995, netball became an International sport recognized by Olympic Committee. . In sports, agility is often defined in terms of an individual sport, because it is an integration of many components that each used differently (i.e. specific to all of sorts of different sports). According to Sheppard and Young (2006), agility is a rapid whole body movement, with change in velocity or direction in response to a stimulus.

Exercise and physical activities helps a lot in the management of some diseases like diabetes, in prevention of cancer and heart problems (Rao, 2010). Players, who are able to sustain a high work-rate throughout the course of a match, gain an advantage over equally skilled players whose energy approach depletion towards the end of a game; or after a series of high intensity efforts, resulting in reduced performance.

\section{PURPOSE OF THE STUDY}

The purpose of this study is to determine the agility ability among korfball players and netball players of Hyderabad District. This study will show the true facts of agility ability among the korfball players and netball players. The study is limited to 20 male korfball players and 20 male netball players of Hyderabad District in India..

\section{METHODOLOGY}

The samples used in this study consist of 20 male korfball players and 20 male netball players. The Illinois Agility Test was used to conduct agility test for both groups. 


\section{A. Illinois Agility Test}

Agility is an important component of many team sports, though it is not always tested and it is often difficult to interpret results. According to Getchell 1979, the Illinois Agility Test is a commonly used test of agility in sports, and due to this, there are many norms available.

\section{B. Equipment required}

The equipments required for this study include flat nonslip surface, marking cones, stop watch, measuring tape, etc.

\section{Procedure}

The length of the course is 10 meters and the width (distance between the start and finish points) is 5 meters. Four cones were used to mark the starting point, finishing points, and the two turning points. Another four cones were placed down the centre, with an equal distance of 3.3 meters apart. Subjects lied on their front (head to the start line) and their hands were placed by their shoulders. On the 'Go' command, the stopwatch was started and the athlete gets up as quickly as possible to run around the course in the direction indicated; without knocking the cones over to the finish line, at which the timing was stopped.

The above test was conducted at Nizam College grounds, Hyderabad separately for both groups with the help of qualified testers.

\section{RESULTS}

Table 1 below shows that netball players have good agility compare to korfball players. The mean of netball players in the shuttle run is 14.31 compare to korfball players of mean 15.57. Agility is very much important for korfball and netball players.

TABLE I. SHOWING MEAN VALUES AND INDEPENDENT Samples Test of Agility Between Netball Players and KORFBALL PLAYERS

\begin{tabular}{|c|c|c|c|c|c|c|c|c|}
\hline Test & GROUP & N & Mean & $\begin{array}{c}\text { Std. } \\
\text { Dev. }\end{array}$ & $\begin{array}{c}\text { Std. } \\
\text { Error } \\
\text { Mean }\end{array}$ & t & df & $\begin{array}{c}\text { Sig. } \\
\text { (2-tailed) }\end{array}$ \\
\hline $\begin{array}{c}\text { Agility } \\
\text { Test }\end{array}$ & $\begin{array}{c}\text { Netball } \\
\text { Players }\end{array}$ & 20 & 14.31 & 0.57 & 0.18 & 2 & 3 & 8. \\
\hline $\begin{array}{c}\text { Agility } \\
\text { Test }\end{array}$ & $\begin{array}{c}\text { Korfball } \\
\text { Players }\end{array}$ & 20 & 15.57 & 1.21 & 0.38 & 4 & 0 & 0.02 \\
\hline
\end{tabular}

\section{DISCUSSION}

Netball is one of the most popular sports in the Europe like basket ball and netball. The performance of netball players depends on the technical skills and physical fitness of the players. The main components and the critical technical skills of netball include agility, explosive strength, and acceleration. Agility is an important motor ability in netball, and the ability to maintain balance, speed, and variety in your movements gives you the upper hand on your opponent on the court.

\section{CONCLUSION}

From the results of this study, it was concluded that netball players have more agility and explosive strength compare to football players. Netball players require quick reflexes, coordination, agility, explosive strength, and techniques to perform well and excel in their games. Hence, physical conditioning training must be given to netball and korfball players to improve their motor qualities such as speed, agility, explosive strength, endurance etc.

\section{ACKNOWLEDGMENT}

My profound gratitude goes to Mr. Vignesh, netball coach of Osmania University, and Dr. E. B. Srikanth, korfball coach of Osmania University for their help in the accomplishment in the study.

\section{REFERENCES}

[1] A. Caterisano, B.T. Patrick, W. L. Edenfield, \& M. J. Batson, "The effects of a basketball season on aerobic and strength parameters among college men: Starters vs. reserves," Journal of Strength and Conditioning Research 11, 21-24. 1997.

[2] K. Shanthi, "Comparative Analysis Of Agility Performance Among Inter District Level Hockey Players," International Journal of Health, Physical Education and Computer Science in Sports, Vol.30 No.1 pp $22-25$

[3] J. P. Rao, "A comparative study on physical fitness among swimmers and Athletics between age group of 12 to 14 years". Asian journal of physical education and computer science in sports, 2, 225-229. 2010.

[4] T. Reilly, and S. Bretherton, Multivariate Analysis of Fitness of female Field Hockey Players. In Perspectives 148 in Kinanthropometry (Edited by J.A.P. Day) Champaign, IL: Human Kinetics, PP.135-142. 1986.

[5] Wikipaedia- Agility

[6] Idea Health and fitness Association. 